\title{
Wind resource modelling in complex terrain using different mesoscale- microscale coupling techniques
}

\author{
D. Carvalho, A. Rocha, C. Silva Santos, R. Pereira
}

\begin{abstract}
Wind resource evaluation in two sites located in Portugal was performed using the mesoscale modelling system Weather Research and Forecasting (WRF) and the wind resource analysis tool commonly used within the wind power industry, the Wind Atlas Analysis and Application Program (WAsP) microscale model. Wind measurement campaigns were conducted in the selected sites, allowing for a comparison between in situ measurements and simulated wind, in terms of flow characteristics and energy yields estimates.

Three different methodologies were tested, aiming to provide an overview of the benefits and limita- tions of these methodologies for wind resource estimation. In the first methodology the mesoscale model acts like "virtual" wind measuring stations, where wind data was computed by WRF for both sites and inserted directly as input in WAsP. In the second approach, the same procedure was followed but here the terrain influences induced by the mesoscale model low resolution terrain data were removed from the simulated wind data. In the third methodology, the simulated wind data is extracted at the top of the planetary boundary layer height for both sites, aiming to assess if the use of geostrophic winds (which, by definition, are not influenced by the local terrain) can bring any improvement in the models performance.

The obtained results for the abovementioned methodologies were compared with those resulting from in situ measurements, in terms of mean wind speed, Weibull probability density function parameters and production estimates, considering the installation of one wind turbine in each site. Results showed that the second tested approach is the one that produces values closest to the measured ones, and fairly acceptable deviations were found using this coupling technique in terms of estimated annual production. However, mesoscale output should not be used directly in wind farm sitting projects, mainly due to the mesoscale model terrain data poor resolution. Instead, the use of mesoscale output in microscale models should be seen as a valid alternative to in situ data mainly for preliminary wind resource assessments, although the application of mesoscale and microscale coupling in areas with complex topography should be done with extreme caution.
\end{abstract}

\section{Keywords:}

Wind energy, Wind simulation, Mesoscale models, Microscale models, WRF, WAsP

\section{Introduction}

Energy is presently considered one of the most valuable commodities in the economical progress and wealth generation of a country, being one of the main driving forces of industrial 
development. Considering the escalating costs of the traditional fossil energy sources, supported by the growing global demand for energy production, an intensive search for alternative sources of energy (preferably renewable ones) has been pursued in the recent past. Among the several available renewable energy sources, wind-derived energy is the one that has witnessed greatest growth in the recent years. Presently, Portugal is one of the world leading countries in terms of installed wind power and this growth is still in progress. In 2011, Portugal was ranked in 10th place worldwide and 5th place among European countries in terms of total wind energy installed capacity [1]. In 2010, Portugal was able to achieve an $18 \%$ quota of wind-derived energy in the total annual energy consumption, outranked worldwide only by Denmark [2]. The current and future expansion of the wind energy markets, combined with the explosive growth of worldwide installed wind power over the last decade and the progressive liberalization of electricity markets, poses several and new challenges to the wind power industry, namely in determining the most appropriate sites for wind energy exploration [3].

Although the use of this renewable energy source has been rapidly increasing worldwide, the lack of reliable and accurate wind measured data in several areas of the globe is still hampering the development of new wind energy projects, and this fact is particularly serious in developing countries [4,5]. Currently, the state of the art in wind resource assessment is based on classical methods that use measured data recorded locally [6], and subsequently inserted as input in microscale models to assess the local wind resource. These methods are still the most reliable for an efficient and realistic planning of potential wind farm sites, meaning higher certainty in the expected available wind resource and lower associated investment risks, which are key prerequisites for the successful development of wind energy projects [7]. However, measurement campaigns have some constraints, namely their high costs, data quality/availability and the need to perform measurements for a representative period, typically with a minimum duration of 1 year. Also, measurement campaigns may reveal that the site has little wind energy potential, which will lead to the irreversible loss of a considerable amount of investment. Moreover, the increasing evolution of the wind energy industry is bringing the need to obtain a preliminary knowledge of the available wind resource at sites with few (or not at all) of local measurements. In these sites, this preliminary knowledge of the local wind regimes is of the utmost importance, at least in a preliminary stage in order to help in the wind resource assessment process.

Considering these disadvantages of the wind measurement campaigns together with the abovementioned growing needs of the wind power industry, the potential benefits of an alternative way to obtain reliable wind data for a spatial mapping and temporal distribution of the wind resource are obvious [8]. Numerical weather prediction (NWP) mesoscale models, which consist of atmospheric models that consider physical phenomena such as frictional, thermal and convective effects, are a very powerful and useful tool to simulate meteorological variables [9]. These mesoscale models can provide "virtual" wind data sets that can be used as input in microscale models, instead of using measured wind data. In the recent past, mesoscale simulations have been used in a considerable number of applications within the wind power area: building wind resource maps in spatially large areas (useful in large scale electrical grid planning and preliminary assessment of potential wind energy exploration sites); computing local long term climatologies to allow the assessment of the wind variability and the representativeness of measurement campaigns (typical for the majority of wind farm projects, in order to estimate the expected annual energy production); and in the growing field of wind power production short term forecasting (due to the need to plan electrical grid balance). However, as with any numerical simulation, the limitations of this approach should be carefully considered on a case-by-case analysis. The use of mesoscale models as source of wind data offers, on one hand, advantages like: low operational costs (most of the mesoscale models are freely available for download and the costs involved in their use are residual); higher sampling resolution (both horizontal and vertical, allowing the computation of virtual wind data sets for several sites at different heights) when compared to wind measuring stations; and they offer data sets with $100 \%$ of availability. On the other hand, there are disadvantages due to the uncertainty associated to wind data derived from these types of models: mesoscale models do not represent the real state of the atmosphere (like real observed measurements do) because atmospheric simulation models are, by definition, an approximation of the real atmosphere; the representation in mesoscale models of the terrain characteristics and physical processes that occur in the atmosphere are simplified.

Nevertheless, the use of mesoscale models as source of wind data for wind resource mapping and/or assessment, either for direct use in microscale models or for studies that do not require a microscale level of detail (wind resource mapping for large areas, for example), has been performed in the recent past with interesting and promising results: [10] performed a wind resource mapping for Norway using the WRF and WAsP models, with results that showed deviations in wind speed between $3 \%$ and $25 \%$ (depending on the local terrain complexity); [11] built a wind atlas for Egypt using the Karlsruhe Atmospheric Mesoscale Model (KAMM) mesoscale model, with deviations in the simulated wind speed between $5 \%$ and $10 \%$, the latter for areas with high local terrain complexity; [12] computed a wind atlas for Spain with the Skiron mesoscale model, and the results showed a wind speed annual bias of $1.87 \mathrm{~m} \mathrm{~s}^{-1}$ over simple terrain and annual bias of $2.5 \mathrm{~m} \mathrm{~s}^{-1}$ over complex terrain; for the Portuguese territory, [13] assessed the wind resource with the WRF model for two distinct sites (one located in a coastal area with low terrain complexity and the other one situated in a mountainous area with high terrain complexity), showing that the WRF model can reproduce the average wind speed with deviations below 5\%; also, [14] conducted a wind energy potential study for the Madeira island with two mesoscale models (MM5 and NH3D), showing that mesoscale models can successfully be applied to the wind resource mapping and enhancing the contribution that these models can offer in the wind resource prediction. Other interesting applications of mesoscale models were found, such as to correct measurements by means of long-term climatology [15] and for short-term wind power forecast [16].

To determine if accurate mesoscale model-based wind power resource assessments can be accomplished, three different methods to couple the mesoscale modelling system WRF with the microscale model WAsP were compared. These methods were tested for an area with high terrain complexity located in Portugal, well known for its wind energy resource where several wind farms are currently in operation and being one of the most important Portuguese areas in terms of installed wind generating power. The use of these methods in wind resource and production estimates will be compared to the traditional methods that rely on measured wind data.

\section{Methodology}

\subsection{Wind measurement data sets}

Data from two wind measuring stations was used in this work. These wind measuring stations collected wind speed and direction measurements at $60 \mathrm{~m}$ above ground level (a.g.l.), with a sampling time resolution of $10 \mathrm{~min}$. The measurements collected at these 
stations during the year of 2008 were selected. This period was considered due to its data availability and quality. The stations are designated as stations $\mathrm{A}$ and $\mathrm{B}$, and are located within the area of the WRF simulation domain, in a central area of the Portuguese mainland. However, the stations and the respective data belong to private companies and their exact locations cannot be disclosed due to data usage restrictions. Nevertheless, it is possible to show in Fig. 1a their relative positions together with the local topography.

The complexity of the terrain around a site can be objectively measured through the ruggedness index or RIX, defined as the percentage fraction of the terrain within a certain distance from a specific site which is steeper than some critical slope, typically

\section{(a)}

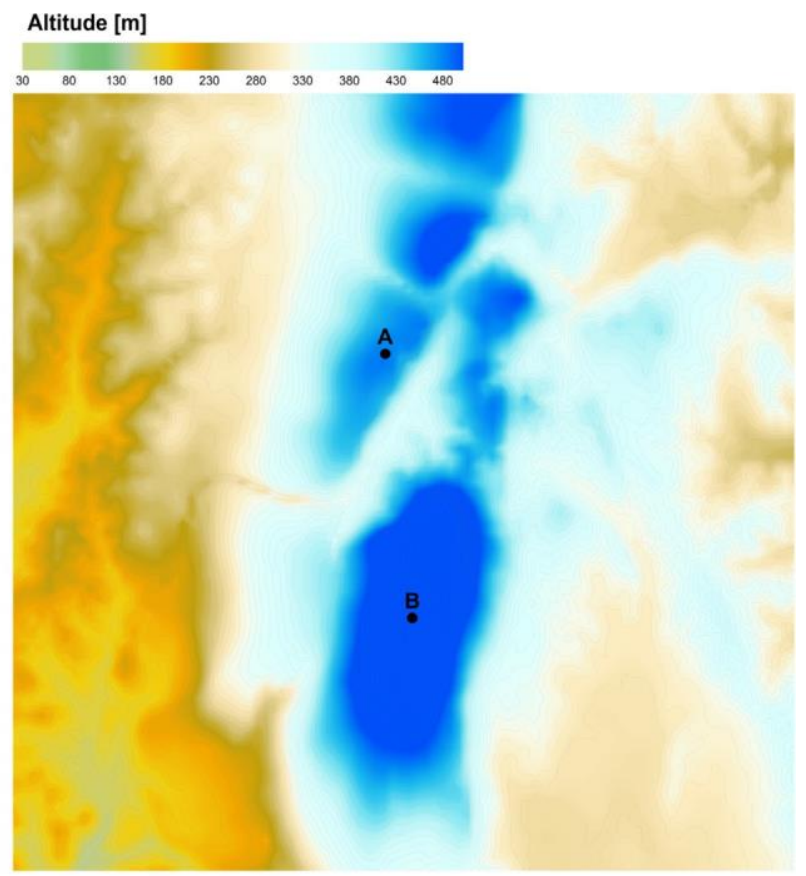

(b)
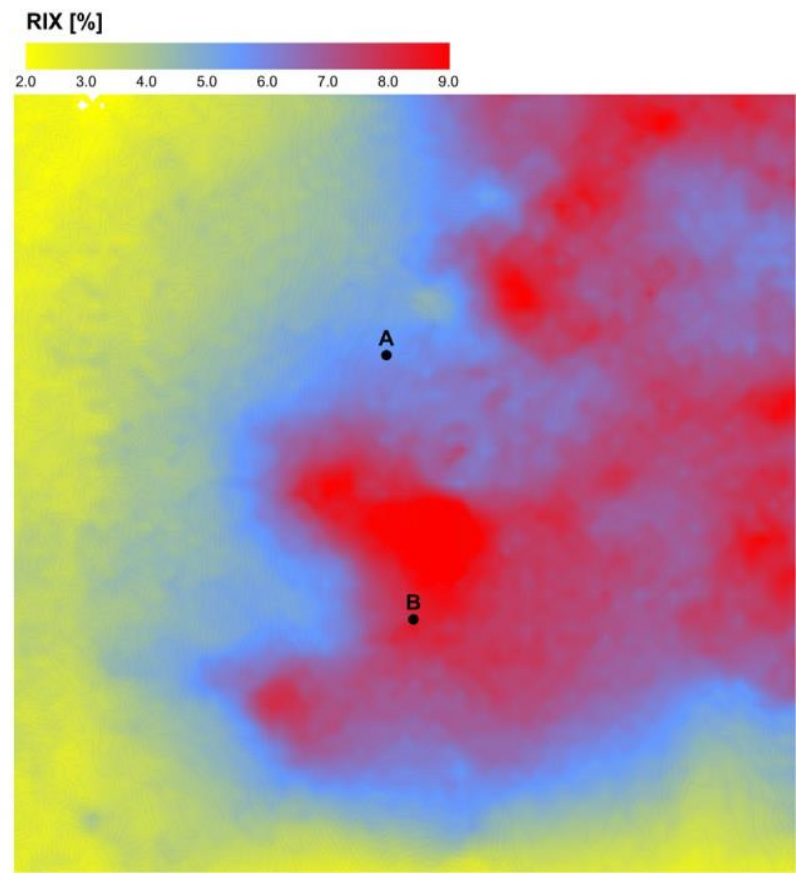

Fig. 1. Wind measuring stations together with the altitude (a) and RIX (b) spatial distributions. considered around 0.3. A detailed description of the RIX index can be found on [17], where basically the RIX is calculated for each of a number of radii originating at the site (wind measuring station or wind turbine). A flat site will then have a RIX of $0 \%$ and an extreme complex (steep) site a RIX index of about $30 \%$, meaning that about one third of the terrain is steeper than the considered critical slope of 0.3. This index can, therefore, be used as a site-specific measure of the terrain complexity, and can describe with a high degree of confidence the effects of local topography and ruggedness on the accuracy of WAsP predictions [17].

The two sites under scope in this work are characterized by different RIX values, meaning that they are located in areas with different terrain complexity. Fig. $1 \mathrm{~b}$ shows the RIX spatial distribution in the area surrounding stations $\mathrm{A}$ and $\mathrm{B}$, being that the site where is located station A has a RIX of $5.9 \%$ and station B site RIX is $8.2 \%$, showing that station $\mathrm{A}$ is located in a less complex site than station B.

\subsection{WRF mesoscale model}

The mesoscale model selected to conduct the simulations is the WRF (Advanced Research-ARW) version 3.0.1, a widely used mesoscale model developed by the National Centre for Atmospheric Research (NCAR). It currently represents the state of the art in mesoscale modelling, and was originally released as a successor to the long standing and well known Penn State/NCAR Fifth-Generation Mesoscale Model (MM5), sharing much of the same dynamics and model physics. A detailed description of this model can be found on [18].

The simulation domains are depicted in Fig. 2. The parent domain (D1) has $90 \mathrm{~km}$ of spatial resolution, covering all of Iberian Peninsula. The first nested domain (D2), with a spatial resolution of $18 \mathrm{~km}$, is centred in the Northern and Central Portugal. The second nested domain (D3), with a spatial resolution of $3.6 \mathrm{~km}$, includes the location of the two sites here considered. The National Centres for Environmental Prediction (NCEP) Final Operational Global Analysis, with $1^{\circ}$ of spatial resolution (both in latitude and longitude) and $6 \mathrm{~h}$ of temporal sampling were used as initial and boundary data.

The complete year of 2008 was simulated with the WRF model, and time series were extracted for the two sites where wind

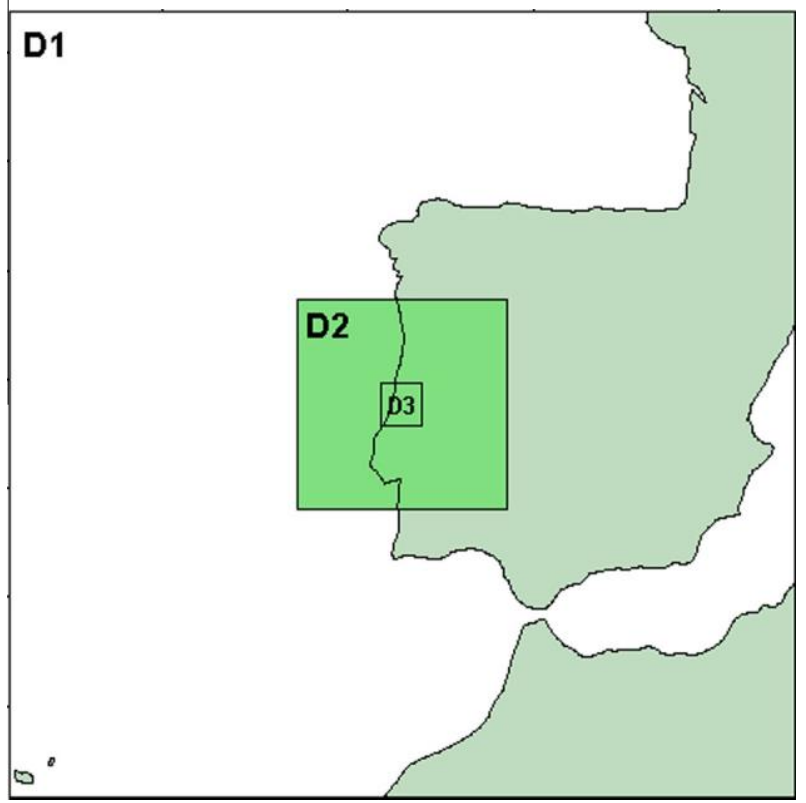

Fig. 2. WRF simulation domains. 
measurement campaigns were conducted. The site that coincides in location with the wind measuring station $\mathrm{A}$ is designated as site 1 and the site that coincides with the location of the wind measuring station B is called site 2. For each site, two wind speed and direction time series were computed: one at $60 \mathrm{~m}$ above ground level (a.g.l.), to match the height where the wind measurements took place, and another one taken above the annual average height of the PBL simulated by WRF for the year of 2008. All the virtual data sets have a sampling rate of $10 \mathrm{~min}$, to coincide also with the sampling rate of the measurements.

\subsection{WAsP microscale model}

The microscale wind flow modelling was performed with the WAsP code, version 9.1. WAsP is still the state of the art software code for microscale modelling of wind resources and overall wind assessment, with a 20 year track record of use by industry [6]. WAsP is especially designed for wind resource mapping, wind farm micro-sitting and energy estimate purposes. WAsP requires, like any atmospheric simulation model, initial conditions that are supplied by observations or mesoscale simulations performed at one or more sites. An important feature of the WAsP model is the ability of generalizing the measured observation at a local site into a regional wind climate - the wind atlas. This model ingests the supplied input data and builds a wind atlas, which consists in a regional wind regime without the effects of the local terrain. For that, the model first removes the topography and ruggedness effects of the supplied data and considers this "free wind" as representative of the entire WAsP simulation domain. This concept of wind atlas arises from the need to build a bridge between measured data in one site and the expected wind regime in a different, but nearby, site. Once a wind atlas is established, the local wind conditions at any site where the wind atlas is valid can be calculated. After the wind atlas computation, the wind regime for any site inside its simulation domain will be computed doing the exactly opposite process. In other words, WAsP takes the wind atlas and re-inserts the terrain characteristics of the selected site to compute its wind characteristics, assuming that the wind climate at any specific site inside the domain may be calculated using the regional climatology described by the wind atlas [19]. More detail of this software can be found on [20].

\subsection{Evaluation of the simulations accuracy}

The comparison between the simulated and measured time series is presented in terms of Weibull probability density function (P.D.F.) parameters $A$ (scale parameter), $k$ (shape parameter), $U_{\mathrm{m}}$ (mean speed) and $U_{\max }$ (most probable wind speed), together with the Weibull P.D.F. curves, annual wind roses of occurrence and of available annual energy production (AEP).

The knowledge of the wind speed frequency distribution is a key factor in the wind energy assessment. If this distribution is known at a given site, then it can be described in terms of a Weibull P.D.F., from which the energetic potential and economic feasibility of this site can easily be obtained [4,5]. This distribution is often used in wind energy engineering, as it conforms well to the observed long-term distribution of mean wind speeds for a range of sites. The Weibull distribution has been widely used to represent wind speed distributions for wind energy applications, not only due to its greater flexibility and simplicity but also because it is able to provide a good fit to experimental data [21-28]. Detailed description of the Weibull P.D.F. and the respective parameters can be found in $[4,5,7,29]$.

The AEP yield estimates and wind roses were computed considering the installation of one wind turbine (from the manufacturer ENERCON, model E-82 with 2.0 MW of nominal power) in the same location of site 1 (2), which coincide with the location of the wind measuring station A (B). The power curve of this wind turbine is depicted in Fig. 3.

\subsection{Mesoscale-microscale coupling techniques}

As previously mentioned, three different methodologies will be tested for the coupling between mesoscale and microscale models, which basically differ between themselves on the type of input data supplied to microscale model.

\subsubsection{Virtual wind measuring stations}

The first methodology consists in taking from the simulated wind data wind speed and direction time series, at the same points (horizontal and vertical) where the measurements were made, and use them as input to the microscale model. This allows a direct comparison between simulated and measured wind, in terms of

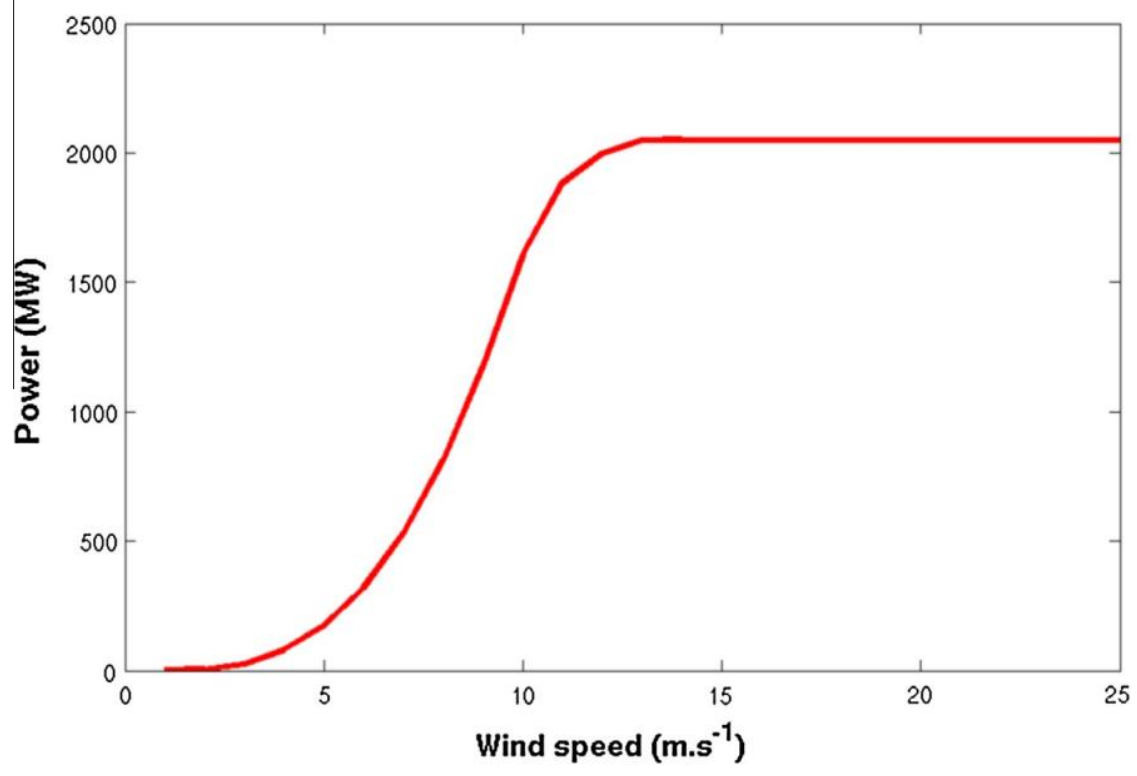

Fig. 3. ENERCON's E-82 wind turbine power curve. 
its characteristics and resulting production estimates. Here, the mesoscale model acts like "virtual wind measuring stations", where wind speed and direction time series are computed for each one of the two sites considered. These wind speed and direction time series will be supplied to WAsP, which will build wind atlases for the sites locations. The computation of the wind atlases consists in removing and re-inserting the terrain effects on the wind data. For this, a map that contains topography and ruggedness information needs to be supplied to WAsP. This map consists of high resolution $\left(3^{10}\right.$, corresponding to approximately $\left.90-100 \mathrm{~m}\right)$ information of topography and ruggedness, making use of the Shuttle Radar Topography Mission (SRTM) data, which obtained elevation data on a near-global scale to generate the most complete high-resolution digital topographic database of the Earth [30]. Also supplied to WAsP is the Corine Land Cover 2000 (CLC 2000) project data, which consists of a vector map of the European environmental land-use derived from satellite images [31], with a spatial resolution of 25 ha (approximately $500 \times 500 \mathrm{~m}$ ). It should be noted that this methodology should not be considered as a real coupling between the models, due to the fact that in this procedure WAsP is simply fed with WRF wind output. This methodology was performed mainly to compare the other two more refined coupling techniques with the traditional results obtained when WAsP is simply fed with WRF wind data, without any concern regarding other issues that are important when coupling mesoscale and microscale models (like topography data differences between the two models).

\subsubsection{Wind atlas using WRF terrain data}

The second methodology is similar to the first one, but introduces an alternative way to build the wind atlas. The default terrain data supplied to the WRF mesoscale model does not have the same quality of the SRTM and CLC 2000, consisting of the GTOPO30 (for terrain elevation) and the U.S. Geological Survey (USGS, for land-use information) data sets, made available by the USGS with a horizontal grid resolution of $30^{10}$ of latitude/longitude (approximately 900-1000 m). In addition to the improved resolution, the CLC2000 data set also has more land use categories than the USGS one (44 instead of 24). Therefore, when WAsP removes the terrain effects from the wind data computed by WRF, it will consider its own high resolution terrain data and not the one used by the WRF model in the wind data computation. This is what was performed in Section 2.5.1. This discrepancy between types and characteristics of terrain data can produce errors, because when WAsP is removing the terrain effects, it is taking into account different terrain data than the one that is, in reality, included in the wind data produced by WRF. In this methodology, the WRF model terrain data was transformed into a map readable by WAsP and the wind atlases were built considering this terrain information. This way, the wind atlases obtained from the WRF model will be properly computed. After this process, WAsP will re-insert the terrain influences in the selected sites in order to compute the local wind characteristics, but now using the high resolution terrain data. Using this methodology, WAsP will remove the WRF low resolution terrain effects from the simulated wind data, and then insert high resolution terrain information leading to a finer scale topography and surface ruggedness features that can have a large impact on low-level wind fields.

\subsubsection{Wind atlas using geostrophic wind}

The third proposed approach aims to test the use of mesoscale simulated winds that are not influenced by the local terrain. It is widely accepted that one of the main limitations of mesoscale models is their oversimplified representation of the real terrain (topography, ruggedness, etc.), due to insufficient detail of the terrain data supplied to the model (as stated above, typically around $30^{10}$ of resolution) and also due to the resolution typically used in the simulation domains (normally between 3 and $5 \mathrm{~km}$ ), clearly not enough to realistically represent the real terrain features. Consequently, the wind simulated by the mesoscale model will have deviations from the real wind due, in part, to this oversimplified terrain representation. Microscale models offer a much more detailed terrain data (topography and ruggedness) but, since microscale models use the mesoscale output to downscale the local wind characteristics, they will receive input wind data from the mesoscale model that took into account terrain data with poor resolution.

In order to extract from the mesoscale model winds that are free (or the closest possible to being free) from the terrain influences, geostrophic winds extracted from the WRF simulations will be used. By definition, the PBL is the lower part of the atmosphere whose behavior is directly influenced by its contact with the planetary surface, mainly due to effects of topography and ruggedness. Above the PBL, the atmosphere is free of the planetary surface influence and the wind is called geostrophic. To this end, the annual mean PBL height was computed for the WRF simulated wind data, taking into account WRF's computation of the PBL height for every time step of its simulations. The annual mean PBL height was approximately $500 \mathrm{~m}$, and the wind time series were extracted at this height. This geostrophic wind (as it is free from the terrain influences) is then used to build a wind atlas in WAsP. This resulting wind atlas computed by WAsP does not take into account any information regarding topography and ruggedness, being that this information is only used when WAsP downscales this wind atlas to the sitelocations.

\section{Results and discussion}

\subsection{Virtual wind stations}

\subsubsection{Comparison between the observed and simulated wind}

The annual wind speed and direction time series for site 1 (2) are taken from WRF and inserted in WAsP, as well as the wind measurements from station A (B). The obtained results are presented in Table 1 and Figs. 4-6.

In terms of the wind speed simulation, it is clear that using this methodology the model significantly underestimates the wind speed for both sites. The simulations foresee lower values for the annual mean and most probable wind speed than those measured by the respective wind measuring stations. The magnitude of the

Table 1

Comparison between Weibull parameters for measured and simulated wind data.

\begin{tabular}{|c|c|c|c|c|}
\hline $\begin{array}{l}\text { Weibull } \\
\text { parameters }\end{array}$ & $\begin{array}{l}\text { Site 1 } \\
\left(\mathrm{m} \mathrm{s}^{-1}\right)\end{array}$ & $\begin{array}{l}\text { Deviation to } \\
\text { measured data (\%) }\end{array}$ & $\begin{array}{l}\text { Site } 2 \\
\left(\mathrm{~m} \mathrm{~s}^{-1}\right)\end{array}$ & $\begin{array}{l}\text { Deviation to } \\
\text { measured data (\%) }\end{array}$ \\
\hline \multicolumn{5}{|l|}{ Measured } \\
\hline A & 8.00 & - & 10.00 & - \\
\hline$k$ & 2.69 & - & 2.51 & - \\
\hline$U_{\mathrm{m}}$ & 7.08 & - & 8.88 & - \\
\hline$U_{\max }$ & 6.73 & - & 8.17 & - \\
\hline \multicolumn{5}{|c|}{ Virtual wind stations } \\
\hline$A$ & 6.20 & -22.5 & 6.40 & -36.0 \\
\hline$k$ & 2.54 & -5.6 & 2.57 & 2.4 \\
\hline$U_{\mathrm{m}}$ & 5.52 & -22.0 & 5.66 & -36.3 \\
\hline$U_{\max }$ & 5.09 & -24.4 & 5.28 & -35.3 \\
\hline \multicolumn{5}{|c|}{ WRF terrain data } \\
\hline$A$ & 8.60 & 7.5 & 10.40 & 4.0 \\
\hline$k$ & 2.53 & -5.9 & 2.47 & -1.6 \\
\hline$U_{\mathrm{m}}$ & 7.60 & 7.3 & 9.26 & 4.3 \\
\hline$U_{\max }$ & 7.05 & 4.7 & 8.43 & 3.2 \\
\hline \multicolumn{5}{|c|}{ Geostrophic wind } \\
\hline A & 7.10 & -11.3 & 8.50 & -15.0 \\
\hline$k$ & 3.20 & 19.0 & 3.05 & 21.5 \\
\hline$U_{\mathrm{m}}$ & 6.38 & -9.9 & 7.59 & -14.5 \\
\hline$u_{\max }$ & $\underline{b .32}$ & -6.2 & 1.46 & $-\gamma .6$ \\
\hline
\end{tabular}



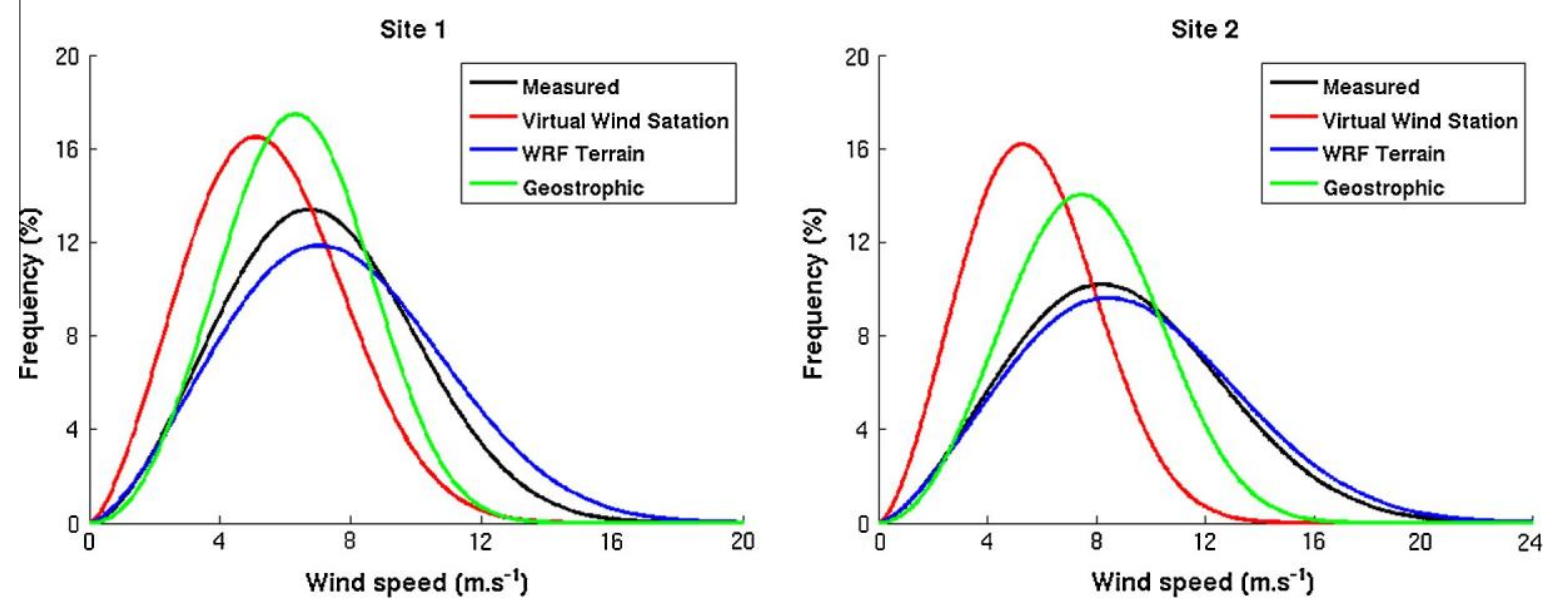

Fig. 4. Weibull P.D.F. curves for measured and simulated wind.

differences is similar in the results for the Weibull scale parameter $A$, but for the shape parameter $k$ the model behavior is quite reasonable. Comparing both sites, it is clear that the model presents a worse overall performance in site 2 .

Fig. 4 clearly reflects the strong wind speed underestimation by the model in both sites. The simulated Weibull curves present a visible shifting to the left side of the wind speed axis, meaning that the model foresees higher frequencies of low wind speeds and, by consequence, lower frequencies of strong wind speeds than in reality. Also, it is visible that the model considers wind speeds around 5$6 \mathrm{~m} \mathrm{~s}^{-1}$ as the most frequent ones, while observations show that, in reality, the most frequent wind speeds are around $7-8 \mathrm{~m} \mathrm{~s}^{-1}$, which is in accordance with the most probable wind speeds values presented in Table 1. Again, the discrepancy between simulated and observed Weibull functions is higher for site 2 .

In terms of the wind direction simulation, Fig. 5 presents the annual occurrence wind roses using simulated and measured data for site 1 and Fig. 6 for site 2. In terms of occurrences on site 1, the observed and simulated occurrence wind roses are quite similar. The model is able to successfully determine the dominant sector, and to reasonably simulate the relative percentage of occurrences of the remaining sectors. In site 2 the results are somewhat worse, as the model considers the north-northwest sector as the most dominant while the observations show that it is the northwest sector that has the highest percentage of occurrences. The distribution of the occurrence frequencies of all sectors in this site appears to be rotated about $25^{\circ}$ clockwise. It is also visible in all the computed results that, while measurements show that the sites have a slightly different wind regime, the model considers both sites with similar wind circulation patterns.

3.1.2. Comparison of the observed and simulated production estimates The resulting values in terms of AEP and AEP wind roses are presented in Table 2 and Figs. 7 and 8 . Looking at Table 2 , and as expected, the wind speed underestimation by the WRF model is strongly reflected in the production estimates. Using the simulated wind data as input in WAsP, the production estimates are clearly lower than those that are based in observed wind data. Again, the model presents poorer performance for site 2 , which is expected due to the worst simulation of the wind speed distribution in this site.

The influence of the wind speed underestimation on the AEP estimates is better explained when the Weibull curves (presented in Fig. 4) are analyzed together with the power curve of the wind turbine here considered. As can be seen in Fig. 3, the cut-in speed (minimum wind speed at which the wind turbine will generate usable power) for this wind turbine is approximately $2 \mathrm{~m} \mathrm{~s}^{-1}$. As shown in Table 1, the simulated average wind speeds for both sites are significantly lower, which will induce lower production estimates. Moreover, Fig. 4 shows that the simulations foresee higher frequencies of wind speeds below $2 \mathrm{~m} \mathrm{~s}^{-1}$ than what was observed. AEP estimates are significantly underestimated due to the prediction of higher frequencies of low wind speeds (part of them below the cut-in speed of the wind turbine that will originate null energy productions) together with lower frequencies of strong winds (which would originate high energy productions).

Fig. 7 shows the AEP wind roses for site 1 and Fig. 8 for site 2. The observed and simulated AEP wind roses for site 1 are quite similar, with the model able to successfully determine the dominant sector and the relative percentage of AEP of the remaining sectors. Again, for site 2 the results are somewhat worse, as the model considers the north-northwest sector as the most dominant while the observations show that it is the northwest sector that has the highest percentage of AEP. The distribution of the occurrence frequencies of all sectors in this site appears to be rotated about $25^{\circ}$ clockwise.

In this methodology it becomes clear that the model main error source is the wind speed underestimation, which is mainly due to the weak terrain representation by the mesoscale model. The mesoscale model represents the terrain in its simulation grid smoother and with a systematic lower topography than in reality and these two factors will produce a wind speed underestimation in its output. On the one hand, it is known that areas with lower altitude are, in general, characterized by lower wind speeds. In fact, the WRF model considers site 1 with $25 \%$ lower altitude than in reality, while site 2 is depicted in WRF simulation domain with less than $50 \%$ of its real altitude. Consequently, if the model sees the simulation point with lower altitude than in reality, the simulated wind speeds for the considered site will be lower than what was measured. On the other hand, mountainous areas frequently give origin to wind speed-up effects. The wind flow suffers a compression on the windy side of the mountain as the flow moves to the mountain top, followed by an expansion when the air masses pass the mountain ridge and flow to the lee side of the mountain, due to

its decompression. Ultimately, if the model represents the terrain as being smoother and the simulation point as being lower than in reality, these speed-up effects will be attenuated, originating an underestimation of the wind speeds.

The combination of these factors, which arise as a consequence of the distorted terrain representation by the mesoscale model, will induce lower simulated wind speeds. As an addition to these factors, the characteristics of the real local topography can also generate physical gradients (thermal, pressure) due to the presence or absence of close mountains that will also contribute to errors in the wind speed simulation by the mesoscale model, which is not able to represent these real topography characteristics. 
(a)
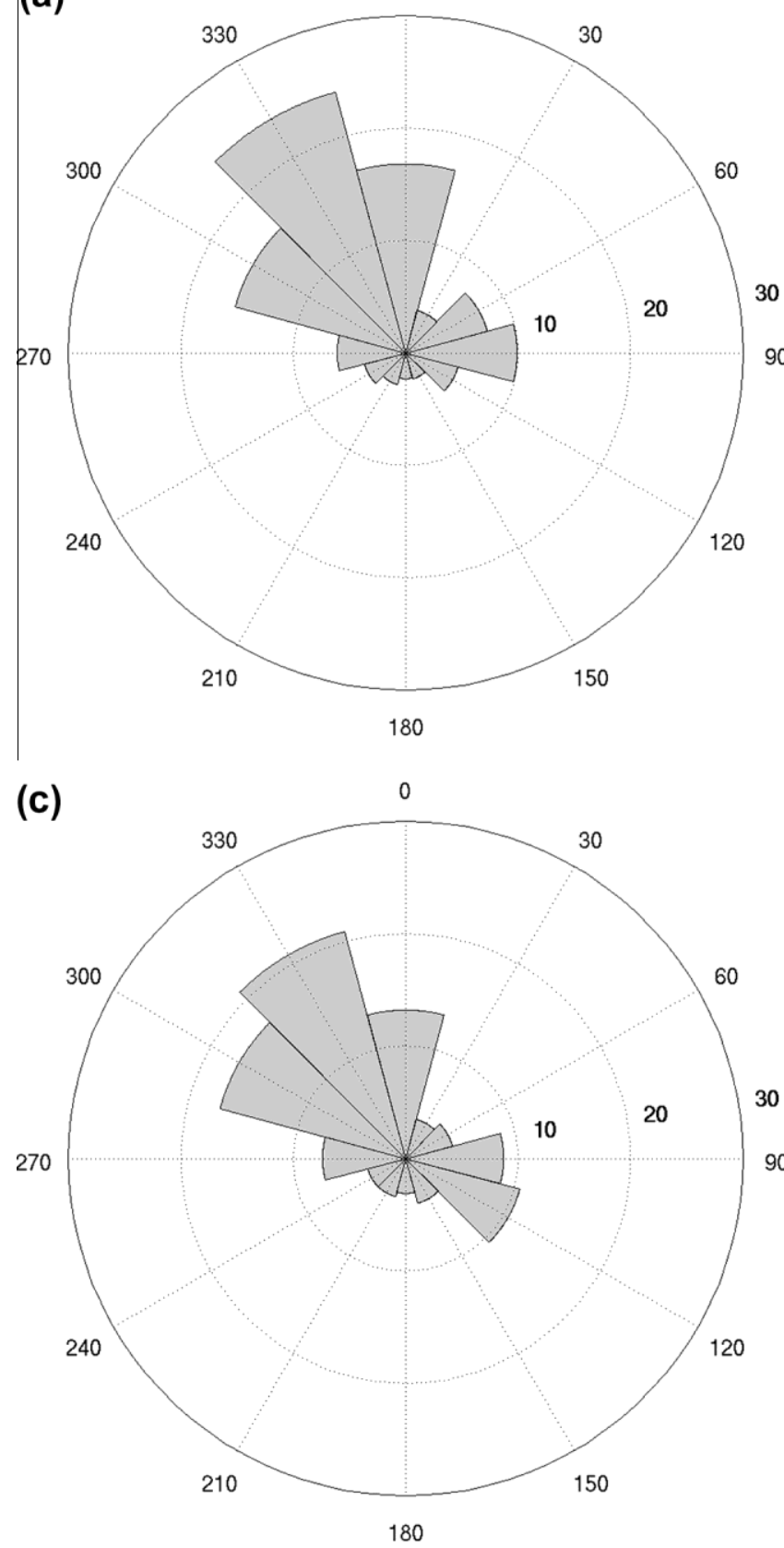

(b)
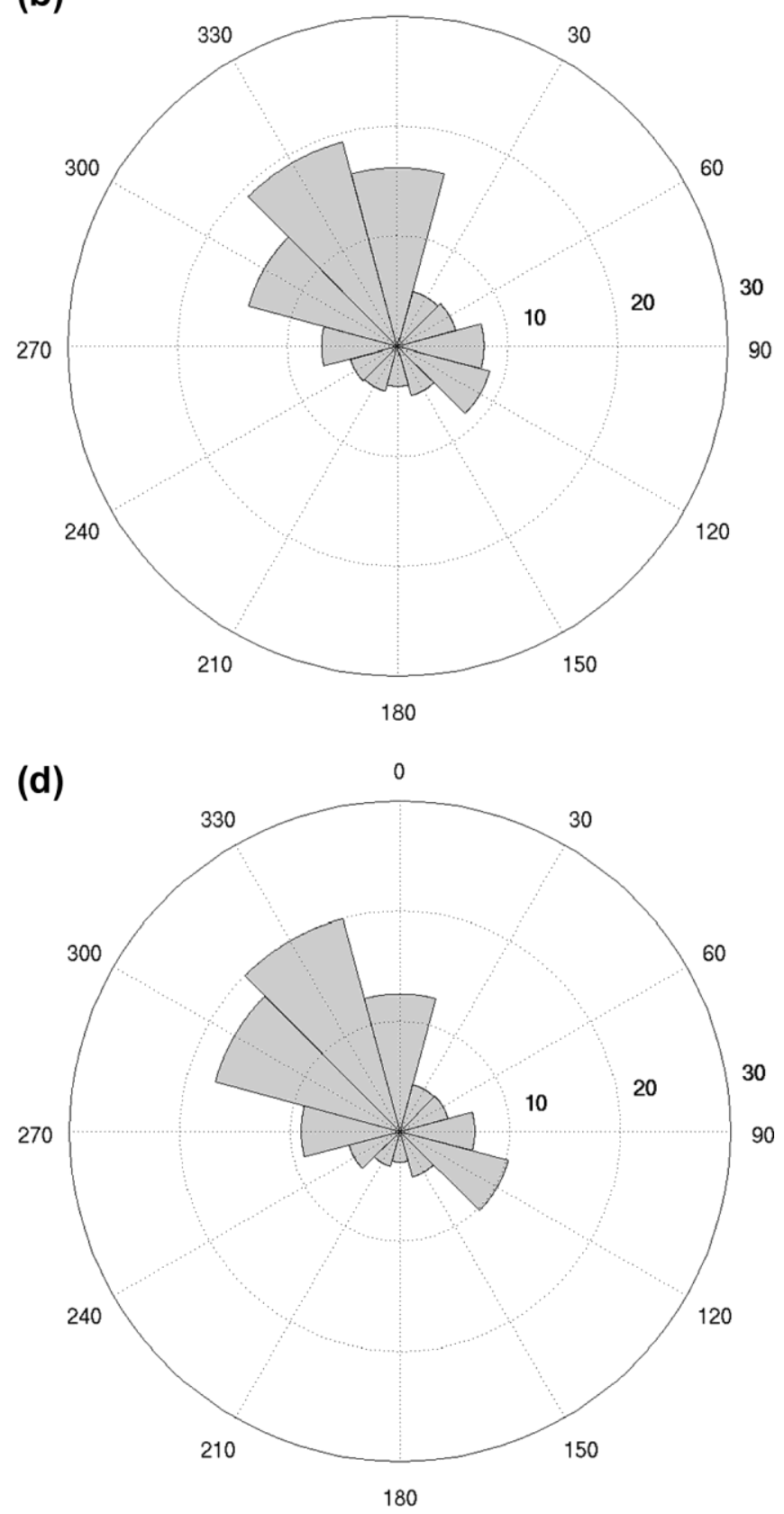

Fig. 5. Occurrences wind roses for site 1 ((a): measured; (b): virtual wind measuring station methodology; (c): WRF terrain data coupling technique; (d): geostrophic wind coupling technique).

Furthermore, results are clearly worse for site 2 showing that the surrounding terrain complexity plays an important role in the wind speed simulation. In this site, located in a more complex terrain than site 1 (as showed in Fig. 1b, with the RIX values for both sites), the limitations of the mesoscale model are more exposed since the mesoscale model representation of the local topography is more distorted.

\subsection{Wind atlas using WRF terrain data}

\subsubsection{Comparison of the observed and simulated wind main characteristics}

The results in terms of the Weibull distribution parameters $A, k$, and $U_{\mathrm{m}}$ and $U_{\max }$, Weibull P.D.F. curves and annual occurrence wind roses are presented in Table 1 and Figs. 4-6.
The model performance is clearly improved when this coupling technique is used. According to Table 1, the wind speed is now slightly overestimated, with deviations of $7.3 \%$ for site 1 and $4.3 \%$ for site 2 in terms of mean wind speed, and of $4.7 \%$ for site 1 and $3.2 \%$ for site 2 in terms of most probable wind speed. The magnitude of the differences is similar for the Weibull scale parameter $A$ and the shape parameter $k$, with the latter being underestimated. Comparing both sites, now the models present a slightly better overall performance for site 2 .

As for the Weibull P.D.F. curves of the observed and simulated wind for both sites depicted in Fig. 4, results clearly show an improvement of the model performance when using this technique, with simulated Weibull curves much closer to the observed ones. An inverse behavior of the models is now visible, since the wind speeds are slightly overestimated for both sites. 
(a)

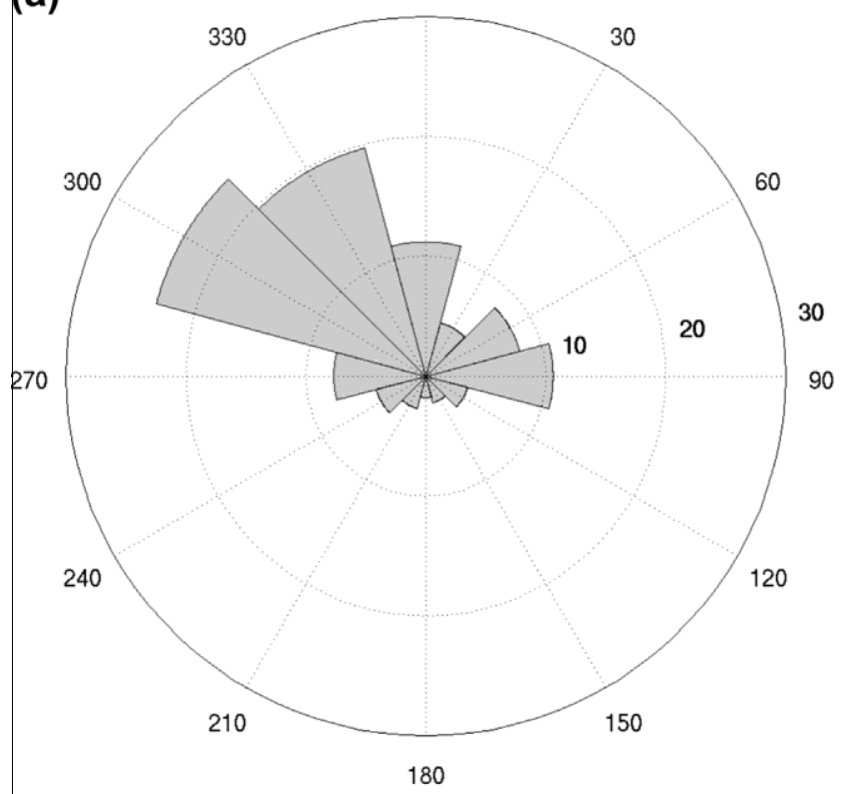

(c)

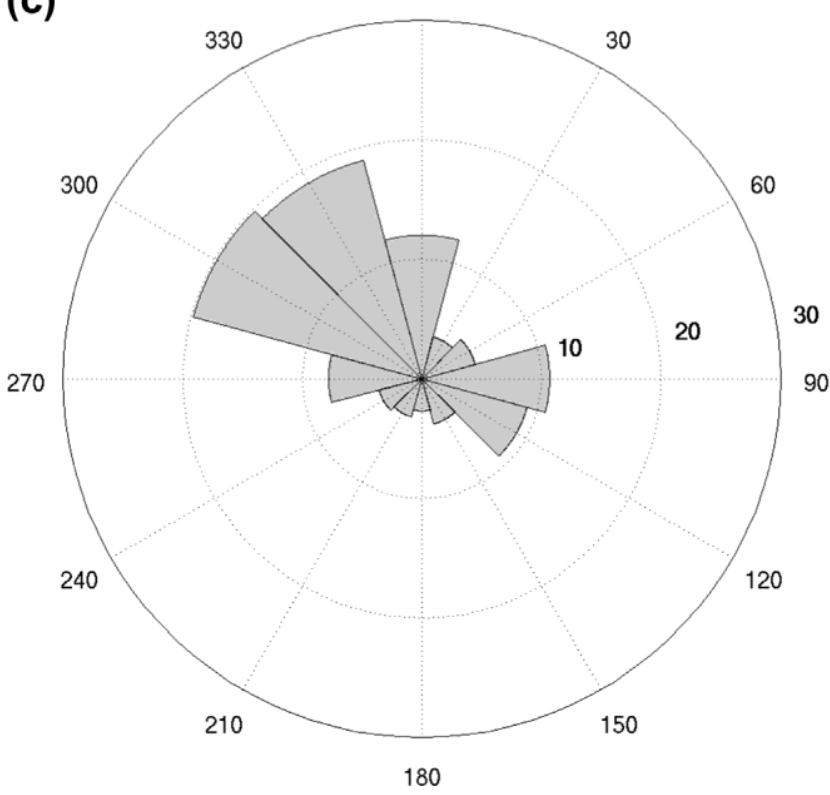

(b)

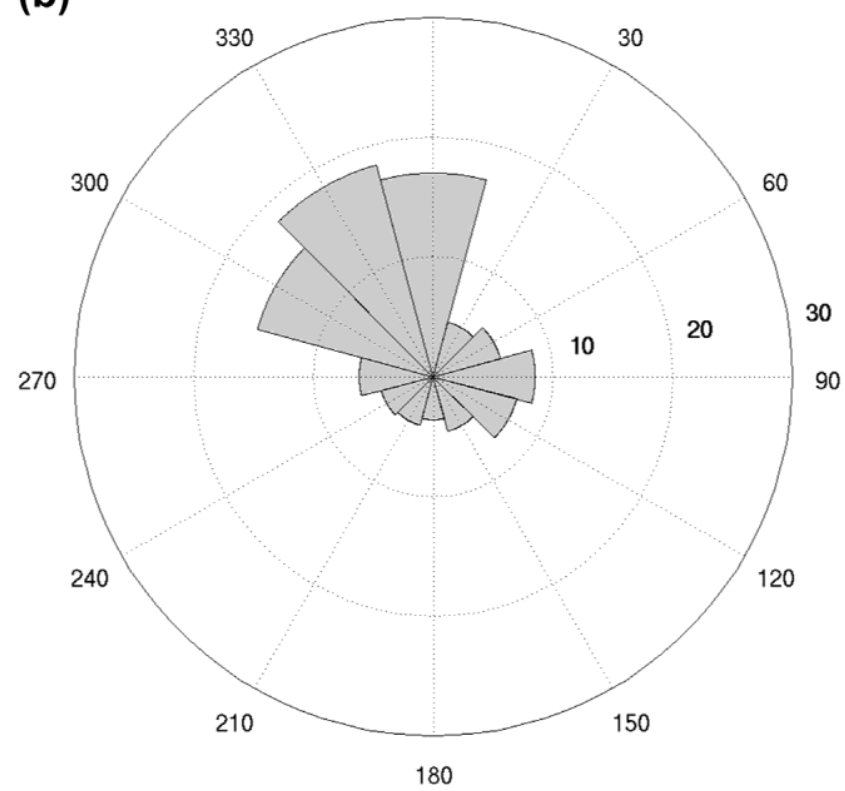

(d)

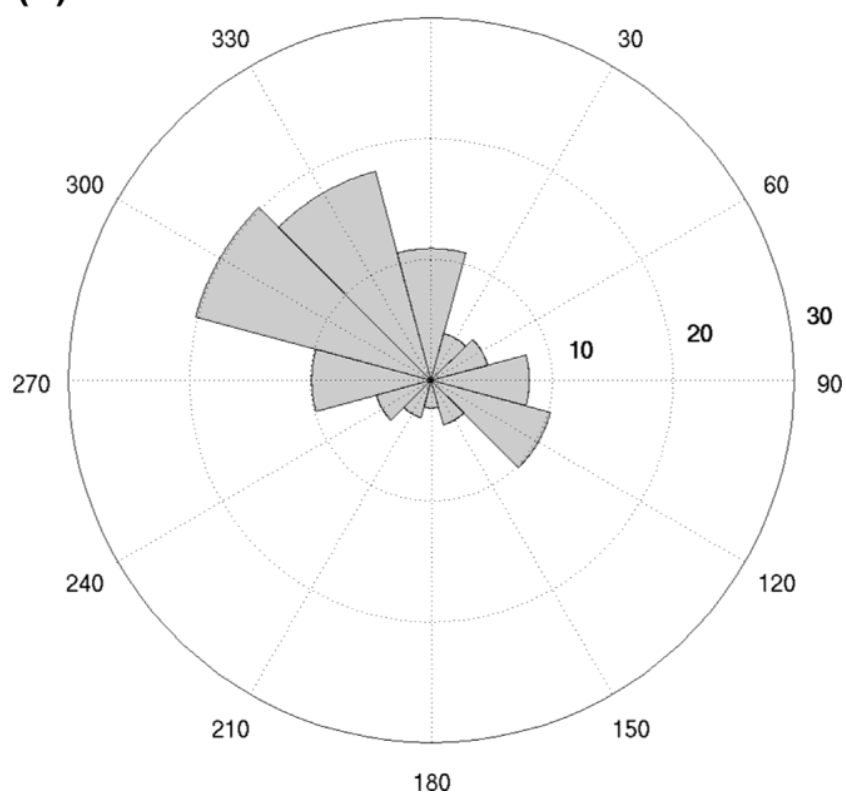

Fig. 6. Occurrences wind roses for site 2 ((a): measured; (b): virtual wind measuring station methodology; (c): WRF terrain data coupling technique; (d): geostrophic wind coupling technique).

Table 2

AEP estimates for both sites using measured and simulated wind data.

\begin{tabular}{llllc}
\hline AEP & $\begin{array}{l}\text { Site 1 } \\
\left(\text { GW h year }{ }^{-1}\right)\end{array}$ & $\begin{array}{l}\text { Deviation to } \\
\text { measured } \\
\text { data }(\%)\end{array}$ & $\begin{array}{l}\text { Site 2 } \\
(\text { GW h year }\end{array}$ & $\begin{array}{l}\text { Deviation to } \\
\text { measured } \\
\text { data }(\%)\end{array}$ \\
\hline $\begin{array}{l}\text { Measured } \\
\text { Virtual wind } \\
\text { stations }\end{array}$ & 6.451 & - & 9.640 & - \\
$\begin{array}{c}\text { WRF terrain } \\
\text { data }\end{array}$ & 7.436 & -46.7 & 3.652 & -62.1 \\
$\begin{array}{c}\text { Geostrophic } \\
\text { wind }\end{array}$ & 4.721 & 15.6 & 10.163 & 5.4 \\
\multicolumn{1}{c}{} & -26.8 & 7.270 & -24.6 \\
\hline
\end{tabular}

This is due to the higher frequencies of wind speeds above $2 \mathrm{~m} \mathrm{~s}^{-}$ ${ }^{1}$, together with the higher frequencies of strong wind speeds in the simulated wind when compared to the measured one. This behavior is more visible for site 1 , but the overall results are fairly good.

In terms of wind direction simulation, Fig. 5 depicts the annual occurrence wind roses for site 1 and Fig. 6 for site 2 using simulated and measured data. The observed and simulated occurrence wind roses present a fairly good agreement between themselves, for both sites. The model is able to successfully determine the dominant sectors, and to reasonably simulate the relative percentage of occurrences of the remaining sectors. The highest deviations are seen in site 2 , where the simulated dominant sector presents a lower occurrence percentage than the observed one. Even so, the results for site 2 are substantially improved with this coupling technique. 
(a)

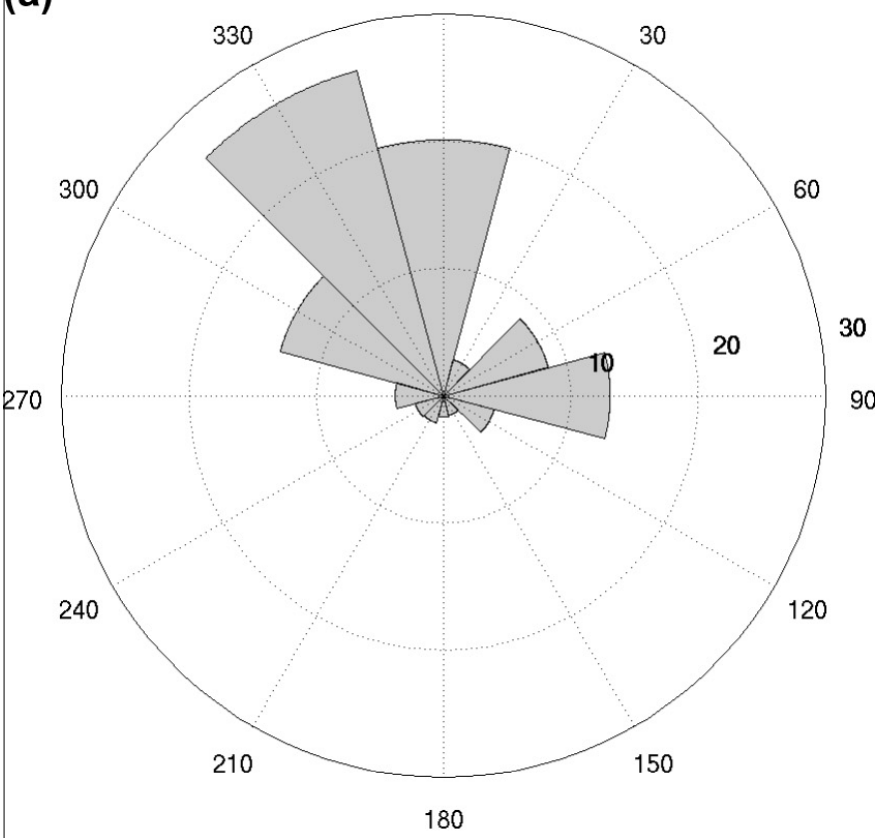

0

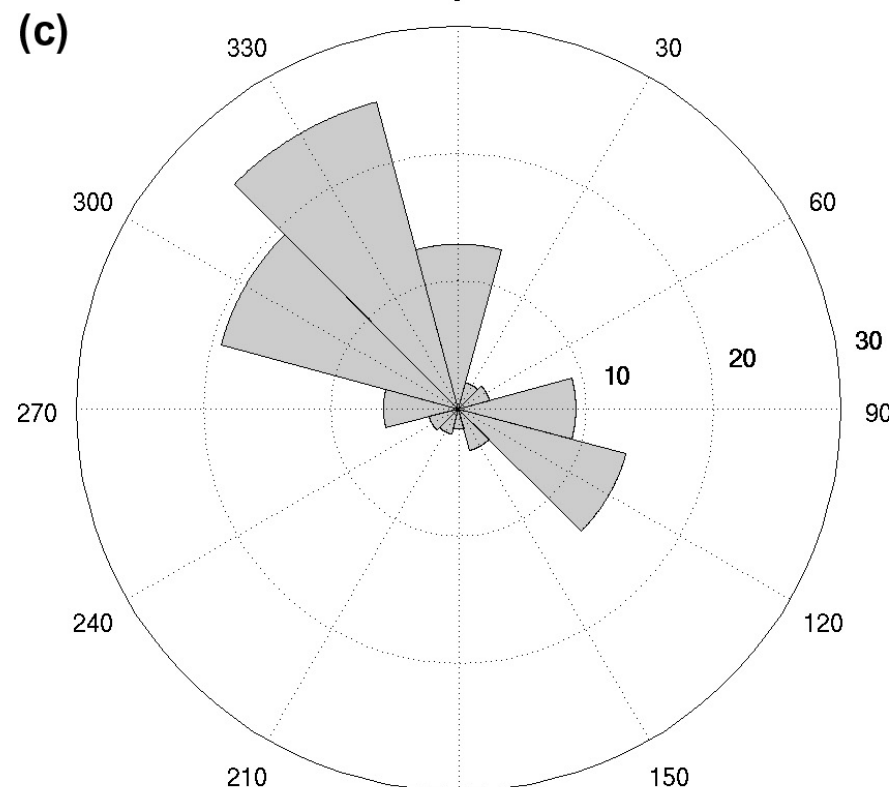

(b)

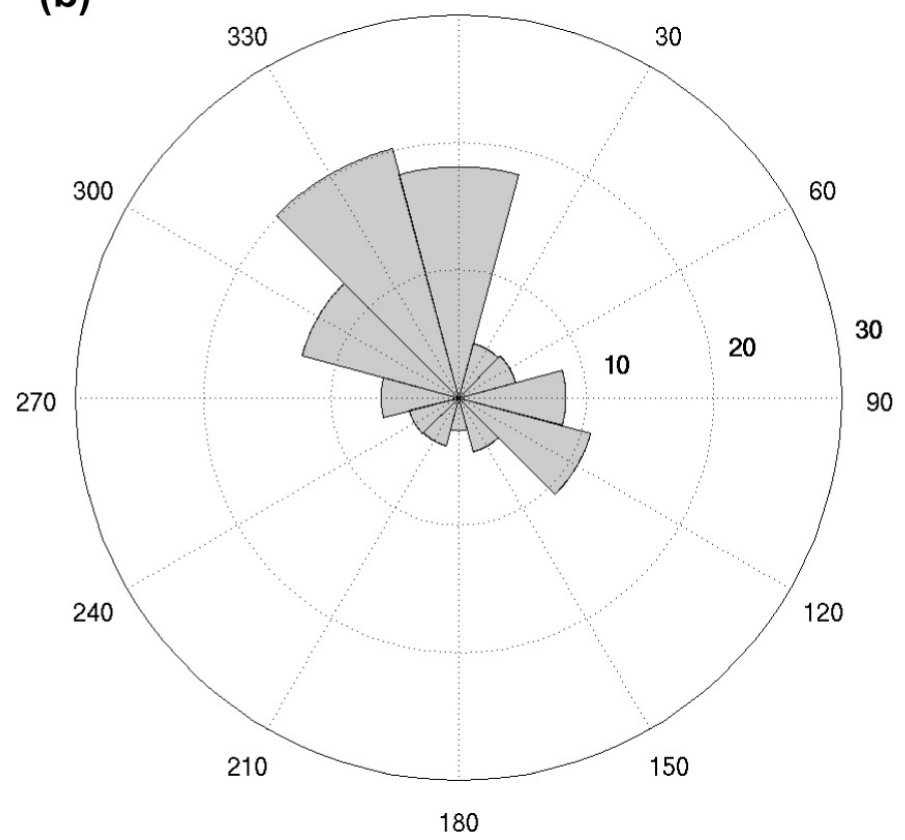

0

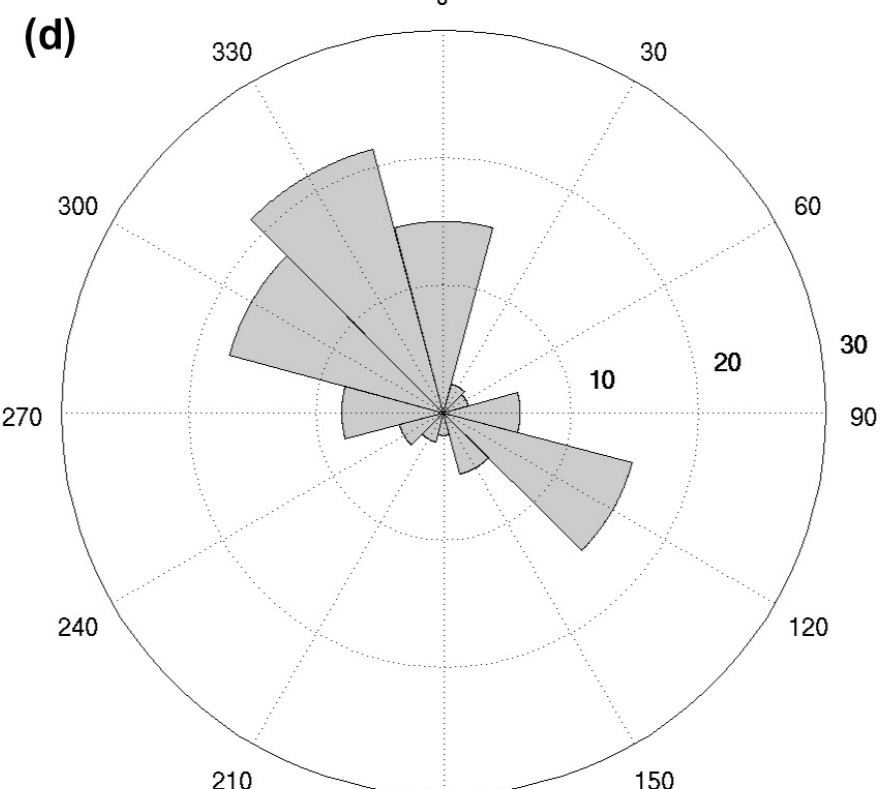

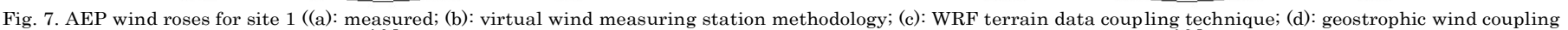
technique).

3.2.2. Comparison of the observed and simulated production estimates

The AEP estimates are presented in Table 2. This methodology produces significantly lower deviations in the AEP estimates when compared to the first methodology. The production is now overestimated, as it was expected, due to the overestimation of the wind speed. The differences between AEP estimates are reasonable for site 1 , but the models present a fairly good performance for site 2. Fig. 7 shows the AEP wind roses for site 1 and Fig. 8 for site 2 . Again, there are no major differences between the observed and simulated wind roses for both sites. The model is able to successfully determine the dominant sector and the relative percentage of AEP due to the remaining sectors.
Overall, results show that this coupling technique was able to provide far better results when compared to the previous methodology, since the differences between simulated and observed wind are dramatically lower. However, and oppositely to what was seen for the previous procedure, in this approach the wind speed is overestimated and results show a better performance of the model for site 2 , that is located in more complex terrain than site 1 . This can be explained by the fact that the WRF terrain data extracted to WAsP describes site 1 with higher altitude than site 2 , when in reality it is the opposite (site 2 has higher altitude than site 1 ). This can lead to the hypothesis that, when WAsP uses WRF's terrain data to build the wind atlases, it considers site 1 as being located 
(a)

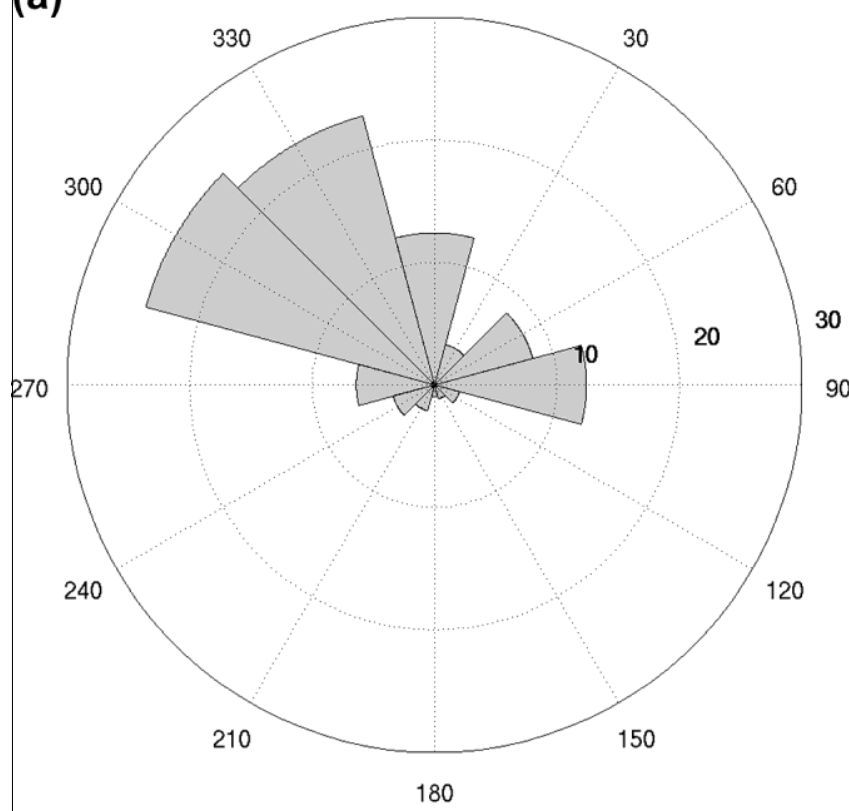

(c)

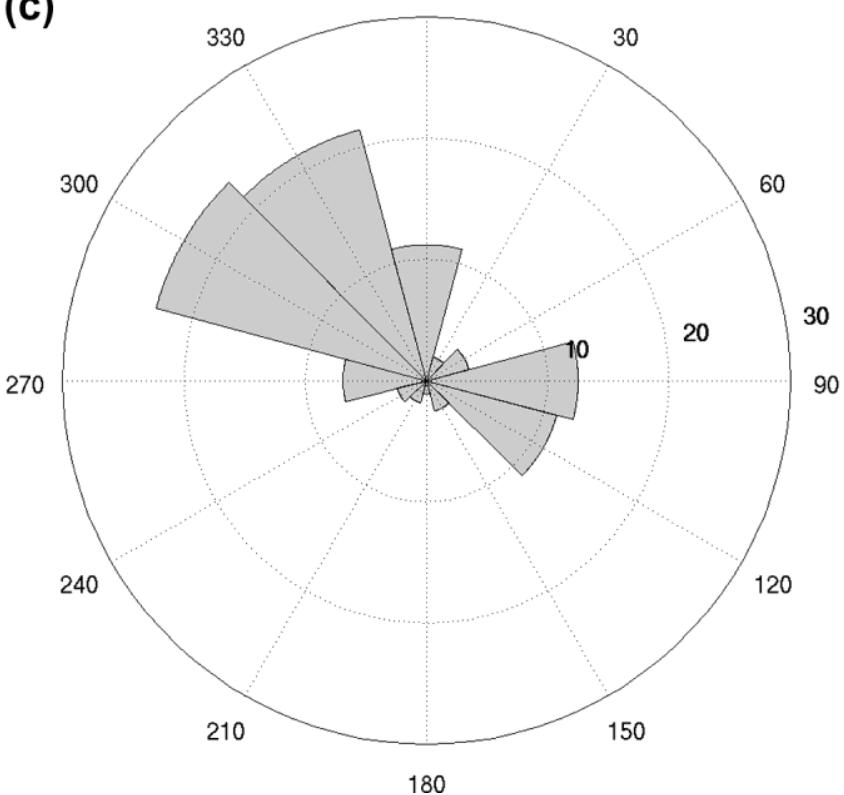

(b)

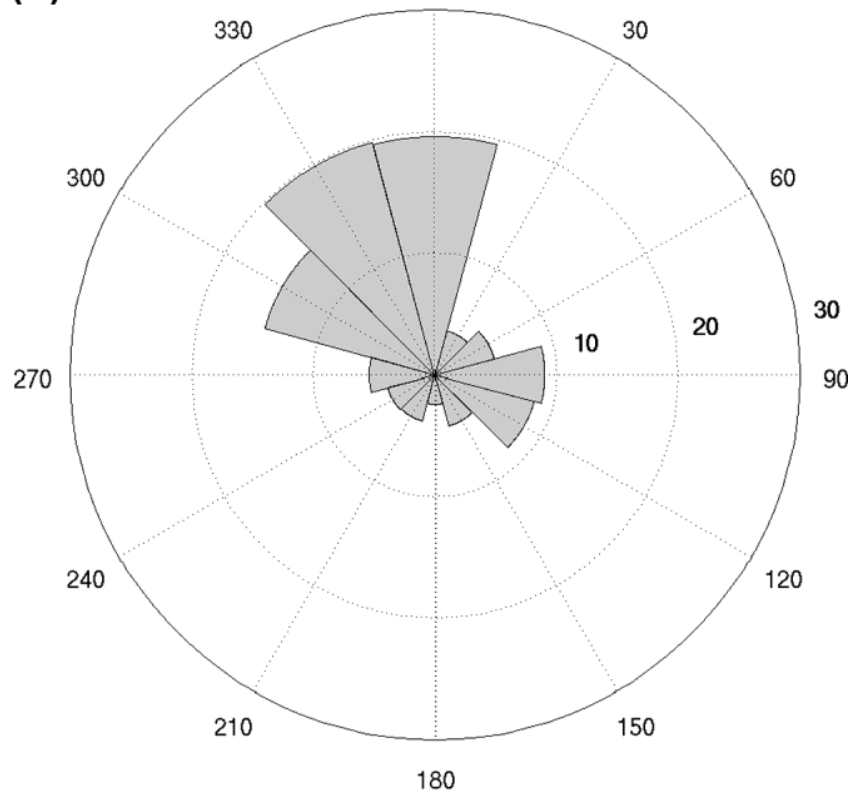

(d)

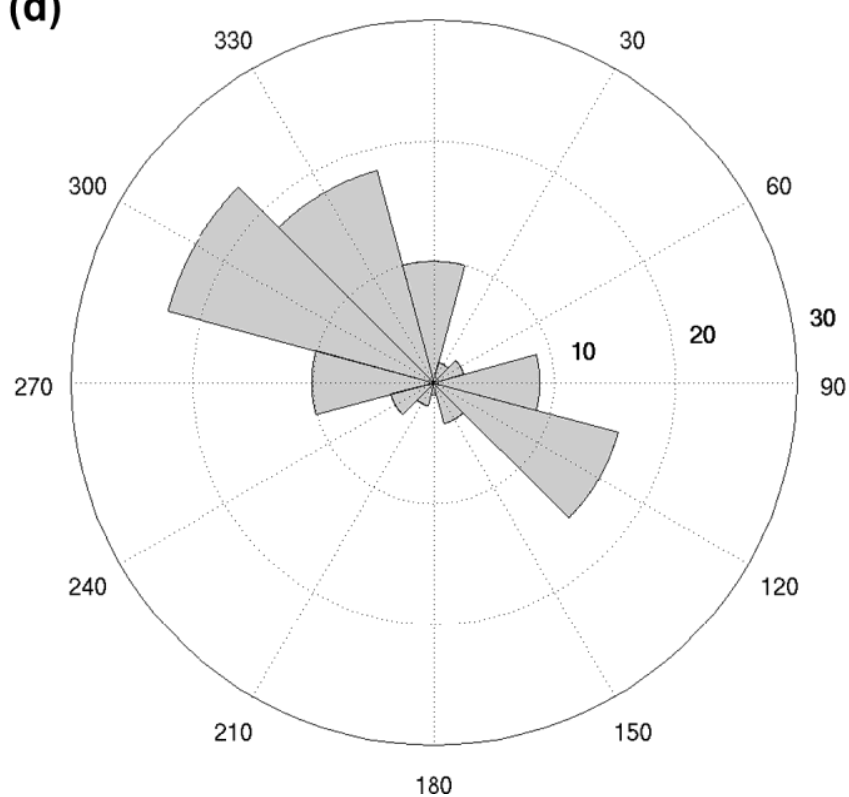

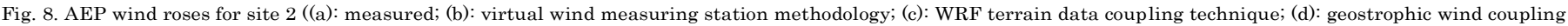
technique).

in more complex terrain than site 2 , leading to worse results in site 1. This is essentially due to issues of poor terrain representation in WRF, which may lead to different levels of terrain smoothing depending on where the mesh nodes lie.

\subsection{Wind atlas using geostrophic wind}

\subsubsection{Comparison of the observed and simulated wind main} characteristics

The obtained results in terms of Weibull distribution parameters $A, k, U_{\mathrm{m}}, U_{\max }$, P.D.F. curves and annual occurrence wind roses are presented in Table 1 and Figs. 4-6.
According to Table 1, this approach shows better results than the first one (Section 3.1.1), but when compared to the previous methodology (Section 3.2.1) its results are clearly worse. Contrarily to what was seen in the previous coupling technique (but in accordance with what was shown for the first methodology), the Weibull shape parameter $A$, mean and most probable wind speed are underestimated and the shape parameter $k$ is overestimated. Again, as it was seen for the first methodology (and in opposition to what was shown in the previous procedure), the higher errors are again seen for site 2 .

The correspondent Weibull P.D.F. curves, presented in Fig. 4, re flect what was concluded for the wind speed (mean and most probable) and Weibull parameters. That is, these P.D.F. curves are 
similar to the ones regarding the first approach, with a clear shifting to the left of the curves that distorts the real wind speed distribution and will originate the underestimation of the wind speed. As for the annual occurrence wind roses for both sites using simulated and measured data (Figs. 5 and 6), the model is able to reasonably simulate the dominant sectors. Moreover, a standardization of the local wind regimes is clear, when they should be more distinct.

\subsubsection{Comparison of the observed and simulated production estimates}

The AEP estimates are presented in Table 2 . As a consequence of the results of this approach for the wind speed and Weibull parameters, this coupling technique clearly produces a strong underestimation of the AEP estimates. Again, the estimates deviation are higher when compared to the previous methodology and lower relatively to the previous one. For site 1 an AEP underestimation of $26.8 \%$ is obtained and for site 2 an underestimation of $24.6 \%$ is computed.

The AEP wind roses, depicted in Figs. 7 and 8, show that for site 1 they are fairly similar, but for site 2 higher discrepancies are detected. Overall results of this approach show that this coupling technique was not able to improve the simulations accuracy, at least when it is compared to the previous one. Although an improvement was detected relatively to the first methodology, the use of a geostrophic approach to overcome terrain effects influence on the simulations is not enough to obtain reliable and realistic results.

\section{Conclusions}

This work was undertaken with the main objective of testing

the performance of three mesoscale-microscale coupling techniques for the wind (speed and direction) and AEP simulation estimates, when compared to the same estimates based in measured wind data. For this purpose, the mesoscale model WRF and the microscale model WAsP were used. Simulations were performed in the exact same locations were wind measurement campaigns

were conducted, allowing the comparison between simulated and observed wind data in terms of atmospheric flow characteristics and production estimates. The sites differ in terms of local terrain complexity in order to analyze the sensitivity of the methodologies performance to these terrain characteristics, which is seen as one of the main sources of error in the near surface winds simulation due to the mesoscale model low resolution terrain data.

The obtained results show that, if the mesoscale output is directly inserted in the microscale model (first approach), the local wind speed distributions are severely misrepresented leading to a strong underestimation of the wind speed and, consequently, of the estimated AEP. These deviations between simulated and measured data are most likely due to the mesoscale model misrepre-

sentation of the local terrain characteristics together with the discrepancies between the terrain effects induced by the mesoscale model and the terrain effects removed by the microscale model when the wind atlases are computed by it. Moreover, this methodology proved that the local terrain complexity is an important factor in the near-surface wind simulation, since worse results were seen for the site located in more complex surrounding terrain.

The second approach, which is an attempt to correct the abovementioned terrain data discrepancies between the mesoscale and microscale model, shows significant improvements in all the results leading to more reasonable values. This coupling technique proves the importance of, when introducing mesoscale-derived wind data in the microscale model, the mesoscale terrain data should be considered. By doing this, the distorted mesoscale-induced terrain effects are successfully removed and, after the subsequent inclusion of high resolution terrain effects, the simulations and AEP estimates become significantly closer to the observed wind data.

The third tested procedure arises as an attempt to completely disregard the mesoscale terrain data in the wind simulation, using geostrophic winds in the wind atlases computation. The obtained results show significant improvement when compared to the first methodology, but presented far worse performance in comparison to the second approach. Therefore, and taking into account the results presented in this study, it is advised to follow the second methodology in order to obtain the most reliable and accurate wind simulations.

Considering these results, it is clear that the quality and accuracy of the models terrain representation (mainly on the mesoscale model, since the microscale model already has terrain data of good quality) is a key factor in near-surface wind simulation, together with the local surrounding terrain complexity. The microscale model WAsP is of linear type and the terrain complexity can induce this model to work outside of its envelope, and if its input data comes already with deviations this limitation of WAsP will be amplified. Both sites are located in a mountainous area, and the local terrain complexity indicates that the application of these (or others) methodologies must be handled with care, since they were obtained solely with numerical simulation models and, therefore, have a considerable degree of uncertainty. Nevertheless, the second methodology presented here showed considerably good results, with a clear improvement of the models performance when compared to the other approaches.

Although encouraging results were obtained, they indicate that the use of mesoscale-microscale models for wind resource assessment purposes cannot still be seen as a substitute to locally acquired wind data for specific wind farm projects, since several sub-grid features are not well represented by the existing parameterizations and terrain data. Nevertheless, it is important to assert that mesoscale-microscale modelling results can be an important factor in initial studies, especially in sites where the terrain is somewhat smooth, or as a tool for preliminary wind resource mapping and assessments.

\section{References}

[1] Global Wind Energy Council. Global Wind Report, Annual market update. $<$ http://www.gwec.net/fileadmin/documents/NewsDocuments/ Annual_report_2011_lowres.pdf>; 2011.

[2] Global Wind Energy Council. Global Wind Energy Report. <http:// www.gwec.net/fileadmin/images/Publications/ GWEC_annual_market_update_2010_-_2nd_edition_April_2011.pdf>; 2010.

[3] Purvins A, Zubaryeva A, Llorente M, Tzimas E, Mercier A. Challenges and options for a large wind power uptake by the European electricity system. Appl Energy 2011;88(5):1461-9.

[4] Ucar A, Balo F. Investigation of wind characteristics and assessment of windgeneration potentiality in Uludağ-Bursa, Turkey. Appl Energy 2009;86(3):333-9.

[5] Ucar A, Balo F. Evaluation of wind energy potential and electricity generation at six locations in Turkey. Appl Energy 2009;86(10):1864-72.

[6] Soares A, Pinto P, Pilão R. Mesoscale modelling for wind resource evaluation purposes: a test case in complex terrain. In: International conference on renewable energies and power quality. <http://www.icrepq.com/icrepq'10/ 433-Soares.pdf>; 2010.

[7] Kwon S-D. Uncertainty analysis of wind energy potential assessment. Appl Energy 2010;87(3):856-65.

[8] Beccali M, Cirrincione G, Marvuglia A, Serporta C. Estimation of wind velocity over a complex terrain using the generalized mapping regressor. Appl Energy 2010;87(3):884-93.

[9] Carvalho D, Rocha A, Gómez-Gesteira M, Santos C. A sensitivity study of the WRF model in wind simulation for an area of high wind energy. Environ Model Softw 2012;33:23-34.

[10] Byrkjedal O, Berge E. The Use of WRF for wind resource mapping in Norway. In: 9th WRF users' workshop; 2008.

[11] Mortensen NG, Hansen JC, Badger J, Jørgensen H, Hasager CB, Paulsen US, et al. Wind atlas for Egypt: measurements, micro- and mesoscale modelling. In: European wind energy conference (EWEC); 2006.

[12] Gastion M, Pascal E, Frias L, Marti I, Irigoyen U, Cantero E, et al. Wind resources map of Spain at mesoscale: methodology and validation. In: European wind energy conference (EWEC); 2008. 
[13] Chagos G, Guides RA, Manso MDO. Estimating wind resource using mesoscale modelling. In: European wind energy conference (EWEC); 2009.

[14] Miranda P, Valente M, Ferreira J. Simulação numérica do escoamento atmosférico sabre a Ilia da Madeira: efeitos não lineares e de estratificação no estabelecimento do potencial eólico na rona do paul da Serra. Technical Report of the Lisbon University Geophysical Centre; 2003.

[15] Cameron WP, Lew D, McCaa J, Cheng S, Eichelberger S, Grimit E. Creating the dataset for the western wind and solar integration study (USA). Wind Eng 2008;32:325-38.

[16] Cassola F, Burlando M. Wind speed and wind energy forecast through Kalman filtering of numerical weather prediction model output. Apple Energy 2012;99:154-66.

[17] Bowen AJ, Mortensen NG. Exploring the limits of WAsP: the wind atlas analysis and application program. In: Proceedings of the European union wind energy conference; 1996. p. 584-7.

[18] Skamarock WC, Kemp JB, Dudhia J, Gill DO, Barker DM, Huang XY, et al. A description of the advanced research WRF Version 3. NCAR Technical Note, Mesoscale and Microscale Meteorology Division of NCAR; 2008.

[19] Troen I, Petersen EL. European wind atlas. Risø National Laboratory, Technical University of Denmark; 1989.

[20] Mortensen NG, Heathfield DN, Myllerup L, Landberg L, Rathmann O. Wind atlas analysis and application program, WAsP 9 Help Facility. Risø National Laboratory, Technical University of Denmark; 2007.

[21] Corotis RB, Sigh AB, Klein J. Probability models of wind velocity magnitude and persistence. Sol Energy 1978;20:481-93.
[22] Garcia A, Torres JL, Prieto E, De Francisco A. Fitting wind speed distributions: a case study. Sol Energy 1998;62:139-44.

[23] Gupta BK. Weibull parameters for annual and monthly wind speed distributions for five locations in India. Sol Energy 1986;37:469-71.

[24] Hennessy Jr JP. A comparison of the Weibull and Rayleigh distributions for estimating wind power potential. Wind Eng 1978;2(3):156-64.

[25] Justus CG, Margraves WR, Mikhail A, Graber D. Methods for estimating wind speed frequency distributions. J App Meteorol 1978;17(3):350-3.

[26] Rehman S, Halawani TO, Husain T. Weibull parameters for wind speed distribution in Saudi Arabia. Sol Energy 1994;53(6):473-9.

[27] Stevens MJM, Smolders PT. The estimation of the parameters of the Weibull wind speed distribution for wind energy utilization purposes. Wind Eng 1979;3(2):132-45.

[28] Takle ES, Brown JM. Note on the use of Weibull statistics to characterize windspeed data. J App Meteorol 1991;30:823-33.

[29] Akpinar EK, Akpinar S. An assessment on seasonal analysis of wind energy characteristics and wind turbine characteristics. Energy Convers Manage 2005;46(11-12):1848-67.

[30] For TG, Risen PA, Caro E, Crippen R, Duren R, Hensley S, et al. The shuttle radar topography mission. Rev Geophys 2007;45(2):1-33.

[31] Büttner G, Feranec J, Jaffrain G, Mari L, Maucha G, Soukup T. The CORINE land cover project. In: Reuter R, editor. EARSeL eProceedings, Paris; 2004. p. 33146. 